\title{
Adoção da tecnologia da informação em organizações rurais: o caso da pecuária de corte
}

\author{
Adoption of information technology in rural organization: \\ the case of beef cattle breeding
}

\author{
João Guilherme de Camargo Ferraz Machado' \\ José Flávio Diniz Nantes ${ }^{2}$
}

\begin{abstract}
Resumo: O objetivo desse trabalho foi estudar o uso e a difusão da TI na pecuária de corte, a partir de fatores que influenciaram a adoção; e descrever recursos, procedimentos e ações necessárias para seu funcionamento. A pesquisa foi realizada em duas fases: uma quantitativa e outra qualitativa. Na primeira, foi realizado um levantamento do tipo survey com produtores, buscando informações acerca das diferentes tecnologias adotadas e das atitudes em relação a elas, possibilitando identificar o grau de inovatividade dos produtores e agrupá-los pela semelhança da postura tecnológica. A segunda analisou experiências, opiniões e perspectivas a respeito da tecnologia integrada ao sistema produtivo de duas propriedades em cada categoria, totalizando dez estudos de caso, a partir de entrevistas pessoais. Os resultados proporcionaram entendimento sobre os motivos da adoção ou rejeição de uma determinada TI, permitindo identificar as razões para alguns produtores adotarem mais rapidamente que outros. Foi possível entender as alterações ocorridas na organização rural por ocasião da implantação dessas tecnologias, observando-se um avanço nas práticas gerenciais a partir da adoção e uso da TI. De um modo geral, os processos foram aprimorados e facilitados, com reflexos positivos em várias áreas da propriedade, incluindo recursos humanos e a imagem do empreendimento no mercado.
\end{abstract}

Palavras-chave: Adoção de tecnologia. Gestão da organização rural. Pecuária de corte. Tecnologia da informação.

\begin{abstract}
This research is aimed to study the use and the diffusion of IT in the beef cattle breeding from the analysis of the factors that have influenced its adoption as well as to describe resources, procedures, and necessary actions for IT operation using case studies in rural properties classified by the innovativeness degree. This study was carried out in two stages, quantitative and qualitative. In the first stage, a survey with producers was conducted. Information concerning the different technologies adopted enabled to identify the level of innovativeness of those producers. They were classified according to the similarities of the technological position. The second stage analyzed experiences, opinions, and perspectives regarding the technology integrated to the productive system. Two rural cattle breeding farms were analyzed in each category through personal interviews totalizing ten case studies. The results indicated the reasons for the adoption or rejection of a certain IT by the producers allowing for the identification of the reasons why some producers have adopted it more quickly than others. It was possible to understand the rural organization modifications due to IT adoption, for example, managerial skills improvements. In general, the processes have been improved and become easier bringing positive effects to several areas including human resources and the enterprise's image in the market.
\end{abstract}

Keywords: Adoption of technology. Farm management. Beef cattle breeding. Information technology.

\section{Introdução}

As alterações no ambiente socioeconômico e institucional vêm impondo às cadeias produtivas agroindustriais significativas transformações, pressionando os empreendimentos rurais a assumirem características empresariais. Novas tecnologias exigem mudanças e adaptações nas organizações rurais, exercendo um forte impacto sobre as estruturas mais conservadoras, cujas estratégias e regras de gerenciamento modificam-se gradual e lentamente, principalmente porque foram desenvolvidas e organizadas para atender a mercados e tecnologias estáveis. Nesse sentido, a principal fonte dessas mudanças tem sido o emprego da informação, associada às tecnologias facilitadoras de coleta,

\footnotetext{
UNESP - Univ Estadual Paulista, Campus Experimental de Tupã, Av. Domingos da Costa Lopes, 780, Jardim Unesp, CEP 17602-496, Tupa, SP, Brasil, e-mail: joao@tupa.unesp.br

${ }^{2}$ Universidade Federal de São Carlos - UFSCar, Departamento de Engenharia da Produção, Rod. Washington Luiz, Km 235, CP 676, CEP 13565-905, São Carlos, SP, Brasil, e-mail: fnantes@ power.ufscar.br
} 
processamento, armazenamento e disseminação (YAMAGUCHI, 2002).

No setor rural, essa situação não é diferente. As organizações tendem a se tornar mais competitivas à medida que incorporam tecnologia em seus processos de produção e comercialização de produtos. Entretanto, a incorporação de tecnologia deve ser realizada com cuidado, em função da realidade do produtor, dos custos de implantação e manutenção, e dos mercados em que a propriedade está inserida.

Dessa forma, torna-se muito importante que os produtores defasados tecnologicamente tenham acesso a ferramentas que permitam tornar o empreendimento mais competitivo. Dentre essas tecnologias, a Tecnologia da Informação (TI) se destaca como uma das ferramentas de gestão administrativa que o agronegócio da pecuária de corte tem sistematicamente incorporado em suas atividades, aumentando a velocidade de transmissão de informação e, ao mesmo tempo, diminuindo seu custo.

Essa tecnologia reúne uma variedade de sistemas e programas de computador e portais existentes na Internet sobre o agronegócio. Ressalta-se que a TI não representa apenas o uso de softwares e computadores. Furlan e Ivo (1992, p. 3) a definiram como sendo "[...] aquela que abrange toda forma de gerar, armazenar, veicular, processar e reproduzir informação", indicando outras aplicações para a TI. Dentre elas, pode-se citar a utilização de dispositivos eletrônicos, visando ao armazenamento de informações relevantes sobre as condições sanitárias, nutricionais e genéticas dos animais (MACHADO, 2002); os canais de televisão, ofertando além de informações, produtos e serviços específicos para a atividade pecuária; e as telecomunicações fixa e móvel.

Assim, torna-se importante estudar o processo de adoção e uso da TI pelos produtores rurais, possibilitando um melhor entendimento dos fatores que afetam sua adoção e utilização, visando nortear ações que permitam ampliar o uso dessa tecnologia. A utilização da TI no empreendimento rural pecuário está relacionada com a confiabilidade das informações referentes à qualidade sanitária do rebanho, item considerado essencial para o processo de rastreabilidade ao longo da cadeia produtiva da carne bovina. Portanto, esse avanço no conhecimento, no tratamento e na disseminação das informações de produção fornecerá subsídios para o desenvolvimento de futuros trabalhos em outros segmentos da cadeia produtiva. No entanto, observam-se lacunas de conhecimento sobre o tema. A literatura trata da adoção de tecnologias no meio rural de duas formas: a primeira se concentra nos motivos da adoção ou rejeição de uma determinada inovação pelos produtores. Exemplos recentes incluem Marra, Pannell e Ghadim (2003), Sheikh, Rehman e Yates
(2003), Batte (2005), Alvarez e Nuthall (2006) e Pannell et al. (2006).

A segunda forma procura identificar as razões de alguns produtores adotarem tecnologias mais rapidamente que outros. São estudos menos frequentes, principalmente, devido às dificuldades na coleta de dados para esse tipo de análise, como o relatado por Batz, Janssen e Peters (2003), Diederen et al. (2003), Hollifield e Donnermeyer (2003) e Adrian, Norwood e Mask (2005). Portanto, na literatura não foram encontrados trabalhos que permitam avaliar o uso e a difusão da TI nos empreendimentos rurais, visando à formulação de ações e/ou políticas públicas e privadas a partir das realidades locais.

Essa situação provavelmente ocorre devido à necessidade de associar, na mesma pesquisa, conhecimentos provenientes das áreas técnica de produção e gerencial do empreendimento. Essas áreas de conhecimento, embora apresentem uma interface muito grande, realizam poucos trabalhos em conjunto. Isso é importante pelo fato da aplicação das ferramentas gerenciais ser facilitada pelo conhecimento prático da atividade, como no desenvolvimento de softwares de gerenciamento da produção, cujo desenvolvedor necessita conhecer em profundidade a atividade, seus processos e objetivos.

Diante disso, o objetivo deste trabalho foi diagnosticar o uso e o perfil do usuário de TI na pecuária de corte, segmento em que essa tecnologia vem se tornando imprescindível, tanto para o gerenciamento da produção, quanto para a conquista e manutenção de mercados consumidores. O objetivo foi identificar os fatores que influenciaram na adoção da TI e segmentar os empreendimentos rurais a partir do grau de inovatividade, visando contribuir para a formulação de ações e/ou políticas públicas e privadas mais adequadas a partir das realidades locais.

\section{Tecnologia da informação}

\subsection{TI no meio rural}

O conceito de TI engloba hardware, software, telecomunicações, automação, recursos multimídia, recursos de organização de dados, sistemas de informação, serviços, negócios, usuários e as relações complexas envolvidas na coleta, uso, análise e utilização da informação (FERREIRA; RAMOS, 2005). Especificamente no agronegócio, Schiefer e Zazueta (2004) relataram que a TI tem o potencial de promover suporte ao setor agroalimentar para que este lide com desafios, sendo também um facilitador para futuros desenvolvimentos. A atual orientação das empresas para a globalização se constroi sobre uma moderna tecnologia de comunicação e é acelerada pela habilidade de uma comunicação tecnológica. Dessa dupla perspectiva, a adoção da TI por membros 
do setor agroalimentar não é mais uma questão de escolha, mas de sobrevivência.

No setor rural, as TI permitem equilibrar algumas desvantagens econômicas, reduzindo as barreiras de tempo e de distância dos principais mercados. Por isso, a TI vem sendo considerada como um importante agente de reestruturação do ambiente e das funções dentro e fora das organizações, por interligar pessoas, processos e empresas. No campo administrativo, os produtores vêm realizando mudanças, a partir da contratação de funcionários mais qualificados, do controle dos custos de produção, da alocação mais adequada de recursos, da padronização dos processos e do estabelecimento de fluxos de produção de acordo com as épocas de maior retorno, da melhoria da qualidade dos produtos (FIGUEIRA et al., 2004).

A existência de grande volume de dados para coletar, processar, armazenar, recuperar e distribuir exige uma transformação dos sistemas de informação manuais em sistemas eletrônicos, visando melhores resultados organizacionais. Para o administrador e/ou produtor rural, isso representa um maior conhecimento de questões técnicas e econômicas da produção, melhorando a sua capacidade de tomada de decisão e de elaboração de estratégias (MINÉU, 2002).

O aumento da utilização da TI pode causar impactos positivos na agropecuária, destacando-se a substituição da força de trabalho e o aumento no controle das atividades, contribuindo para a redução da incerteza e dos riscos. Dessa forma, é possível esperar que sua incorporação no dia a dia da propriedade aumente o ingresso aos mercados, por facilitar o acesso à informação.

A adoção da TI é particularmente importante na pecuária, na qual os sistemas informatizados armazenam e fornecem informações sobre o controle de matrizes, cruzamento de animais, inseminações artificiais, aspectos nutricionais e sanitários de cada animal. O gerenciamento dessas informações pode ser realizado por meio de softwares específicos.

\subsection{Fatores que influenciam a adoção de TI}

De acordo com Rogers (1995), os fatores que influenciam a adoção de TI podem ser reunidos em três grupos: a) status socioeconômico; b) variáveis de personalidade; e c) comportamento de comunicação.

a) Status socioeconômico: nesse grupo encontram-se os fatores: educação; cultura; status social mais elevado; mobilidade social progressiva; unidades de tamanho maior; orientação comercial, em vez de subsistência (adotantes atrasados); atitude mais favorável ao crédito; e operações mais especializadas. Os produtores inovadores, em geral, possuem propriedades maiores e maior contato com os agentes de mudança. Além disso, produtores com condições econômicas favoráveis adotam antes uma inovação, que geralmente possui maior custo e, por isso, demanda maior investimento inicial. O autor relatou que não há relação entre idade e inovatividade, existe uma relação positiva entre status social (renda, nível de vida, posse de riquezas, prestígio ocupacional) e inovatividade, e os produtores mais inovadores possuem maior mobilidade social em direção aos mais altos status.

b) Variáveis de personalidade: as principais generalizações positivas em relação às variáveis de personalidade são: empatia; racionalidade; inteligência; atitude favorável à mudança; habilidade para lidar com incertezas e riscos; e atitude favorável em relação à educação.

c) Comportamento de comunicação: as principais generalizações em relação ao comportamento de comunicação, positivamente associadas à inovatividade incluem: participação social; contato com os agentes de mudança; exposição aos canais de comunicação interpessoais e em massa; busca por informações sobre inovações; conhecimento sobre inovações; e liderança de opinião.

A adoção de tecnologia está intimamente relacionada com a predisposição para tecnologia que, por sua vez, é resultado de crenças e sentimentos positivos e negativos do consumidor (PARASURAMAN, 2000; PARASURAMAN; COLBY, 2001).

\subsection{Obstáculos à adoção de TI}

Juntamente com os benefícios que a TI proporciona, surgem obstáculos relacionados à seleção, implantação, uso e manutenção da tecnologia. São, geralmente, custos relacionados à aquisição da TI e à sua efetiva utilização (FREITAS; RECH, 2003). Santos Junior et al. (2005) destacaram que os indivíduos e as empresas reagem de diferentes maneiras diante da TI, como: fascínio, perplexidade, deslumbramento ou descrença; há os que aceitam as novas tecnologias sem maiores questionamentos, enquanto outros relutam em aceitá-las. Assim, ao analisar os obstáculos que as organizações enfrentam ao adotarem novas TI e as ações que tomam para tentar resolvê-los, Freitas e Rech (2003) e Santos Junior et al. (2005) verificaram a ocorrência de problemas referentes ao uso inicial da TI nas empresas, que podem interferir no processo de adoção, como a questão do treinamento, falta de suporte técnico, de políticas motivacionais, resistência cultural à mudança, 
tempo exigido para torná-la eficiente e produtiva, e o custo de sua implantação.

Por esses motivos, a implantação da TI em organizações rurais deve ser feita com muita atenção. A adoção da TI nos empreendimentos rurais deve priorizar a coleta de dados e receber uma atenção especial do administrador. É fundamental que as pessoas envolvidas na coleta desses dados estejam comprometidas com o processo, além de serem bem treinadas e orientadas.

\section{Métodos de pesquisa}

$\mathrm{O}$ foco da pesquisa foi dirigido à pecuária de corte, por ser esta uma atividade que, na década de 1990, iniciou um processo de profundas transformações tecnológicas, visando aumentar a competitividade do setor. No que diz respeito às TI, essas mudanças estavam relacionadas à rastreabilidade do rebanho, para garantir a segurança do alimento ao mercado consumidor.

Neste trabalho foram consideradas as TI aplicadas ao processo de produção de carne (coleta e armazenamento de dados zootécnicos, como os dispositivos de identificação eletrônica de animais, computadores, softwares e balança eletrônica) e à gestão da organização. Esse item inclui os sistemas de informações gerenciais e os produtos e serviços de base tecnológica, capazes de proporcionar facilidades diárias, tais como, operações bancárias informatizadas, comunicação à distância, entretenimento com Internet e compras eletrônicas.

Foi proposto um método para a avaliação dos fatores que influenciam o uso e a difusão da TI, cujo objetivo também era descrever recursos, procedimentos e ações necessárias ao funcionamento da TI e identificar as dificuldades no processo de adoção. Os fatores foram separados em três conjuntos distintos, em função do momento da adoção da TI, denominados de: i) fatores antecedentes à adoção; ii) fatores do processo de adoção da TI; e iii) impactos da adoção da TI.

A pesquisa foi realizada em duas etapas: uma quantitativa e outra qualitativa. Na quantitativa, foi realizado um levantamento do tipo survey com aplicação de um questionário estruturado para produtores rurais, cuja atividade principal é a pecuária de corte. A amostra foi constituída a partir do quadro de associados de uma Associação de Criadores, contatada por meio de um Informativo enviado por correio bimestralmente a um grupo de 2.000 associados. A escolha dessa amostra se mostrou adequada devido à heterogeneidade proporcionada, com uma boa distribuição geográfica no País e com características diferenciadas em suas criações.

$\mathrm{O}$ instrumento de coleta foi projetado para coletar dados relevantes à adoção da TI e a seu uso e difusão à atividade pecuária. Os resultados do survey foram utilizados para: a) diferenciar grupos distintos de adotantes, com base no "tempo" de adoção a partir da categorização proposta por Rogers (1995); e b) identificar tendências, questões e interesses para serem verificados posteriormente, durante as entrevistas.

$\mathrm{Na}$ etapa qualitativa, os objetivos foram obter informações acerca das diferentes tecnologias adotadas e dos fatores que motivaram a adoção. Para isso, foram conduzidas entrevistas semiestruturadas com produtores, analisando experiências, opiniões e perspectivas, em relação à tecnologia integrada ao sistema produtivo. Os produtores escolhidos contemplaram as cinco categorias identificadas anteriormente, de acordo com o grau de inovatividade de cada grupo. Foram definidos dois entrevistados por grupo, totalizando dez estudos de caso. A definição dos entrevistados se deu a partir de uma análise da literatura recente sobre adoção e difusão de tecnologia no meio rural.

\section{Resultados}

\subsection{Caracterização da amostra de produtores}

Nessa etapa da pesquisa, a taxa de retorno dos questionários, somando-se as respostas por carta e pela Internet, foi de 3,1\% do total de questionários enviados. De acordo com McDaniel e Gates (2003, p. 211), os índices de resposta em surveys realizados pelo correio podem variar de menos de 5,0\% para mais de 50,0\%, dependendo da extensão do questionário, conteúdo, população pesquisada e incentivos empregados. Nesse caso, um possível motivo para o baixo retorno foi a característica da população pesquisada, composta por produtores rurais não habituados a participar desse tipo de pesquisa. Apesar do índice de respostas ser inferior ao esperado, os dados obtidos possibilitaram a realização das análises previstas, caracterizando satisfatoriamente a amostra.

\subsubsection{Características dos produtores}

As principais características demográficas e socioeconômicas da amostra são apresentadas na Tabela 1.

A maior parte dos produtores $(55,74 \%)$ se concentra na faixa etária entre os 36 e 55 anos. A faixa etária da amostra pode ser considerada relativamente baixa, pois $85,25 \%$ dos produtores têm idade inferior a 55 anos. Essa informação é importante, pois a idade geralmente está relacionada à receptividade do produtor à adoção de novas tecnologias. Foi identificada, ainda, a predominância do sexo masculino entre os pecuaristas, que representaram $96,77 \%$ da população amostrada.

Com relação às características socioeconômicas, foi observado que $73,77 \%$ dos produtores 
Tabela 1. Características demográficas e socioeconômicas da amostra.

\begin{tabular}{crcrccc}
\hline \multicolumn{2}{c}{ Idade (anos) } & \multicolumn{2}{c}{ Renda $(\mathbf{R} \mathbf{)}$} & \multicolumn{3}{c}{ Grau de instrução } \\
\hline Faixa etária & $\mathbf{( \% )}$ & $\begin{array}{c}\text { Renda mensal } \\
\text { familiar }\end{array}$ & $\boldsymbol{( \% )}$ & Escolaridade & $\begin{array}{c}\text { Produtor } \\
(\boldsymbol{\%})\end{array}$ & $\begin{array}{c}\text { Administrador* } \\
(\boldsymbol{\%})\end{array}$ \\
\hline $18-25$ & 9,84 & $2.500,00-4.500,00$ & 11,48 & $1^{\circ}$ grau incompleto & 1,61 & 16,67 \\
$26-35$ & 19,67 & $4.500,00-6.000,00$ & 6,56 & $1^{\circ}$ grau completo & 1,61 & 16,67 \\
$36-45$ & 24,59 & $6.000,00-10.000,00$ & 26,23 & $2^{\circ}$ grau incompleto & 1,61 & 10,00 \\
$46-55$ & 31,15 & $10.000,00-20.000,00$ & 21,31 & $2^{\circ}$ grau completo & 9,68 & 18,33 \\
$56-65$ & 13,11 & + de 20.000,00 & 26,23 & Superior incompleto & 12,90 & 0 \\
+ de 66 & 1,64 & Não sabe & 8,20 & Superior completo & 58,06 & 25,00 \\
& & & Pós-graduação & 14,52 & 5,00 \\
\hline
\end{tabular}

*8,33\% das propriedades não possuem administradores contratados. Fonte: dados da pesquisa.

apresentaram renda mensal familiar entre $\mathrm{R} \$ 6.000,00$ e R \$ 20.000,00. Verificou-se um alto índice de pecuaristas com curso superior completo $(72,58 \%)$, dos quais $14,52 \%$ possuem cursos de pós-graduação. Dentre esses produtores, encontram-se advogados, engenheiros civis, administradores, engenheiros agrônomos, médicos veterinários, zootecnistas, médicos e analistas de sistema. Já em relação aos administradores, observa-se que $30,00 \%$ possuem curso superior completo, dos quais, $5,00 \%$ com pós-graduação.

\subsubsection{Características das propriedades}

A Figura 1 apresenta a localização das propriedades que compuseram a amostra, indicando maior concentração em Mato Grosso do Sul e São Paulo, com 20,59\%, Mato Grosso, com 13,24\%, Goiás com $11,76 \%$ e Roraima, com $10,29 \%$. Cerca de $90 \%$ dos produtores reside na cidade, fato que pode facilitar a adoção de TI que permita o gerenciamento do negócio à distância. Entre a população da amostra, 26,79\% residem até $50 \mathrm{~km}$ da propriedade.

A distância entre a moradia desses produtores e suas propriedades varia muito. Dentre os $17,86 \%$ dos produtores que residem a distâncias superiores a $500 \mathrm{~km}$, muitos deles residem em estados diferentes, o que eleva essas distâncias a $2.000-3.000 \mathrm{~km}$. Com isso, a importância da TI como ferramenta de gestão da propriedade aumenta, permitindo o acompanhamento do negócio e do mercado à distância. A Tabela 2 indica a área destinada à pecuária de corte, o tamanho do rebanho e os grupos de distâncias e o percentual de produtores em cada um desses grupos.

Observa-se que $47,28 \%$ das propriedades que fizeram parte da amostra destinam áreas à pecuária de corte entre 500 e 2.500 ha. Esses valores são expressivos e retratam uma situação frequentemente encontrada na pecuária do Centro-Oeste, principal região participante da amostra. Como consequência dessa situação, o tamanho do rebanho também é

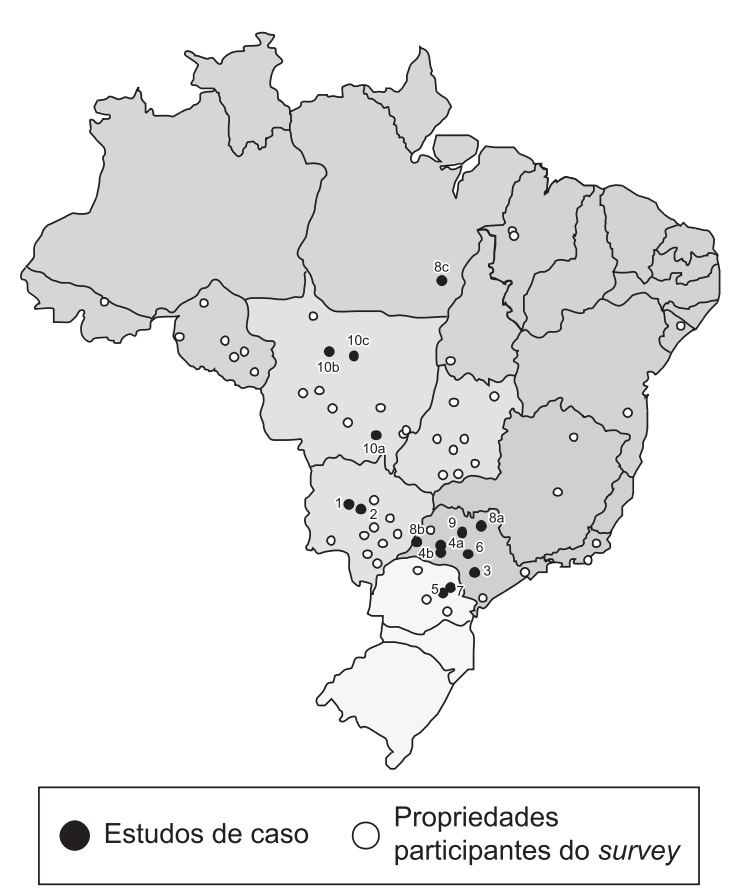

Figura 1. Distribuição geográfica das propriedades participantes. Fonte: dados da pesquisa.

expressivo, uma vez que $56,14 \%$ das propriedades possuem rebanhos entre 1.001 e 5.000 animais.

\subsubsection{Infraestrutura}

A Tabela 3 destaca os produtos e serviços tecnológicos, de uso exclusivo para a atividade pecuária, que os produtores possuem, pretendem adquirir nos próximos 12 meses ou não pretendem adquirir. Além dessas informações, são apresentados os serviços tecnológicos aplicados à atividade pecuária utilizados nos últimos 12 meses e se pretendem utilizá-los nos próximos 12 meses.

Quase a totalidade dos entrevistados possui telefone celular, computador e Internet em casa. Destaca-se 
Tabela 2. Distância entre a moradia e as propriedades, área destinada à pecuária de corte e número de animais que compõem o rebanho das propriedades da amostra.

\begin{tabular}{|c|c|c|c|c|c|}
\hline $\begin{array}{l}\text { Distância entre moradia } \\
\text { e propriedade }\end{array}$ & $(\%)$ & $\begin{array}{c}\text { Área destinada à pecuária } \\
\text { (ha) }\end{array}$ & $(\%)$ & $\begin{array}{l}\text { Número de } \\
\text { animais }\end{array}$ & $(\%)$ \\
\hline Até $50 \mathrm{~km}$ & 26,79 & Até 250 & 12,73 & Até 500 & 14,04 \\
\hline De $51 \mathrm{a} 100 \mathrm{~km}$ & 17,86 & $250-500$ & 12,73 & $500-1.000$ & 14,04 \\
\hline De 101 a $500 \mathrm{~km}$ & 37,50 & $500-1.000$ & 23,64 & $1.000-2.500$ & 29,82 \\
\hline Mais de 500 km & 17,86 & $1.000-2.500$ & 23,64 & $2.500-5.000$ & 26,32 \\
\hline- & - & $2.500-5.000$ & 10,91 & $5.000-10.000$ & 7,02 \\
\hline- & - & $5.000-10.000$ & 5,45 & $10.000-20.000$ & 5,26 \\
\hline - & - & $10.000-25.000$ & 5,45 & + de 20.000 & 3,51 \\
\hline- & - & $25.000-50.000$ & 5,45 & - & - \\
\hline
\end{tabular}

Fonte: dados da pesquisa.

Tabela 3. Posse de produtos/serviços e uso de serviços tecnológicos.

\begin{tabular}{|c|c|c|c|}
\hline Produto/Serviço tecnológico & Já possui $(\%)$ & $\begin{array}{l}\text { Pretende adquirir nos } \\
\text { próximos } 12 \text { meses }(\%)\end{array}$ & $\begin{array}{l}\text { Não pretende } \\
\text { adquirir }(\%)\end{array}$ \\
\hline $\begin{array}{l}\text { Identificação eletrônica de animais } \\
\text { (brinco, código de barras, leitor etc.) }\end{array}$ & 50,88 & 22,81 & 26,32 \\
\hline Balança eletrônica & 72,13 & 16,39 & 11,48 \\
\hline $\begin{array}{l}\text { Software para administração } \\
\text { (contabilidade, custos etc.) }\end{array}$ & 70,49 & 18,03 & 11,48 \\
\hline Software para produção (manejo, sanidade etc.) & 62,71 & 27,12 & 10,17 \\
\hline Assinatura de TV por satélite (canais específicos) & 79,03 & 6,45 & 14,52 \\
\hline Telefone celular & 98,36 & 1,64 & 0 \\
\hline Computador em casa & 98,39 & 1,61 & 0 \\
\hline Computador na propriedade & 57,63 & 23,73 & 18,64 \\
\hline Internet em casa & 96,72 & 0 & 3,28 \\
\hline Internet na propriedade & 28,57 & 30,36 & 41,07 \\
\hline SISBOV (acesso à base de dados) & 50,88 & 35,09 & 14,04 \\
\hline Serviço tecnológico & $\begin{array}{c}\text { Usou nos últimos } \\
12 \text { meses }(\%) \\
\end{array}$ & $\begin{array}{c}\text { Pretende usar nos } \\
\text { próximos } 12 \text { meses }(\%)\end{array}$ & $\begin{array}{c}\text { Não pretende } \\
\text { usar }(\%)\end{array}$ \\
\hline Transação bancária por telefone & 63,79 & 1,72 & 34,48 \\
\hline Transação bancária pela Internet & 60,66 & 3,28 & 36,07 \\
\hline Compra de gado ou sêmen pela Internet & 20,69 & 27,59 & 51,72 \\
\hline Compra de gado ou sêmen pela TV (leilão) & 59,68 & 14,52 & 25,81 \\
\hline $\begin{array}{l}\text { Troca eletrônica de informações } \\
\text { com fornecedor e/ou cliente }\end{array}$ & 65,57 & 22,95 & 11,48 \\
\hline Participação em grupos de discussão pela Internet & 22,03 & 44,07 & 33,90 \\
\hline Treinamento on-line para qualquer tecnologia & 33,90 & 40,68 & 25,42 \\
\hline
\end{tabular}

Fonte: dados da pesquisa.

que o número de produtores que possuem computador e Internet na propriedade é expressivamente inferior aos que possuem essas TI em casa, sugerindo a possibilidade de um gerenciamento à distância das atividades agropecuárias. Essa situação pode ser confirmada pelo fato de $90 \%$ dos produtores residirem na cidade, dos quais, $17,86 \%$ a distâncias superiores a $500 \mathrm{~km}$.

Destaca-se também que 41,07\% dos produtores informaram não estarem dispostos a adquirir serviços de Internet para a propriedade. Um dos motivos para essa resistência pode ser resultado da ausência de infraestrutura adequada para a prestação desse serviço.

Outra tecnologia que se destacou pela resistência na sua adoção foi a identificação eletrônica de animais, na qual 26,32\% dos produtores informaram não pretender adquiri-la. A justificativa para essa postura pode estar fundamentada no custo elevado da tecnologia ou mesmo na integração com os sistemas já existentes.

A Tabela 3 mostra, ainda, que 59,68\% dos produtores utilizaram a televisão como um canal de compra de animais ou de sêmen, demonstrando ser esse um canal significativo para a comercialização 
de insumos. O uso da Internet como um meio de comercialização de animais e sêmen apresentou um alto grau de resistência para 51,72\% dos produtores, que não pretendem usá-la para esse fim, concordando com o resultado de Francisco (2003), em que a Internet é mais utilizada para busca por notícias do setor, cotação de preços e análise do mercado.

A troca eletrônica de informações com fornecedores e/ou clientes apresentou um alto índice de aceitação, com $65,57 \%$ dos pecuaristas indicando seu uso nos últimos 12 meses. Acredita-se que os produtores tenham considerado esse serviço de forma mais abrangente, a partir do uso de $e$-mails.

\subsection{Apresentação dos casos}

Os resultados estão apresentados em função do momento da adoção da TI e contemplam os cinco grupos de adotantes de tecnologia, propostos por Rogers (1995). Rocha e Christensen (1999) destacaram que essas categorias são tipos ideais, que não encontram perfeita correspondência na realidade, mas que são úteis para o melhor entendimento do processo. As características de cada categoria são apresentadas no Quadro 1.

Os aspectos utilizados na categorização dos produtores foram a experiência com as TI e as atitudes do entrevistado em relação a ela. A quantificação da inovatividade foi obtida a partir da soma do (i) nível de experiência (1 para nenhum até 5 para intenso) indicado pelo entrevistado e (ii) o nível de concordância (1 para discordo totalmente até 5 para concordo totalmente) indicado para cada uma das questões relacionadas à inovatividade.

Com essa escala, o score máximo esperado era 85 e o mínimo 17. O resultado da amostra ficou dentro desse intervalo e, quando traçado um gráfico, se assemelhou a uma curva normal padrão, assumindo normalidade para os dados. A verificação dessa normalidade se deu por meio de um teste de normalidade utilizando o software estatístico MINITAB 13. As categorias de adotantes de Rogers (1995) e os resultados individuais de inovatividade foram utilizados para predizer quantos indivíduos da amostra pertenciam a cada categoria (Figura 2).

Os procedimentos estatísticos foram aplicados ao score total. As porcentagens de cada categoria foram aplicadas ao número de entrevistados, resultando, na divisão da amostra em cinco grupos. Com base na distribuição dos entrevistados nessas categorias, foram escolhidos os produtores rurais que participaram da segunda fase da pesquisa, os quais responderam outro questionário, a fim de aprofundar os aspectos que os levaram a adotar cada tecnologia. Para cada grupo foram realizados dois estudos de caso.

\subsubsection{Antecedentes da adoção}

Nesse item são apresentadas as expectativas iniciais, o desenvolvimento e a coordenação do processo de adoção da TI dentro do universo pecuário e as características macroeconômicas quando da adoção da tecnologia, para os cinco grupos de adotantes. Os antecedentes da adoção de TI estão sintetizados no Quadro 2.

\section{a) Inovadores}

As expectativas das duas propriedades quanto à adoção de TI não foram confirmadas em relação ao uso de softwares de controle de produção, em razão da dificuldade encontrada na captação de informações, por deficiência do funcionário. Os resultados demonstraram uma constante preocupação dos gestores com a coleta de dados e com o comprometimento dos funcionários. Machado e Nantes (2000) sugeriram que para superar a geração de informações de baixa qualidade, é necessário qualificar e instruir os funcionários sobre a importância do evento, anteriormente a qualquer ação de caráter tecnológico, para evitar o comprometimento das informações anotadas.

O cenário existente na época de adoção das tecnologias (política, legislação, acesso a crédito,

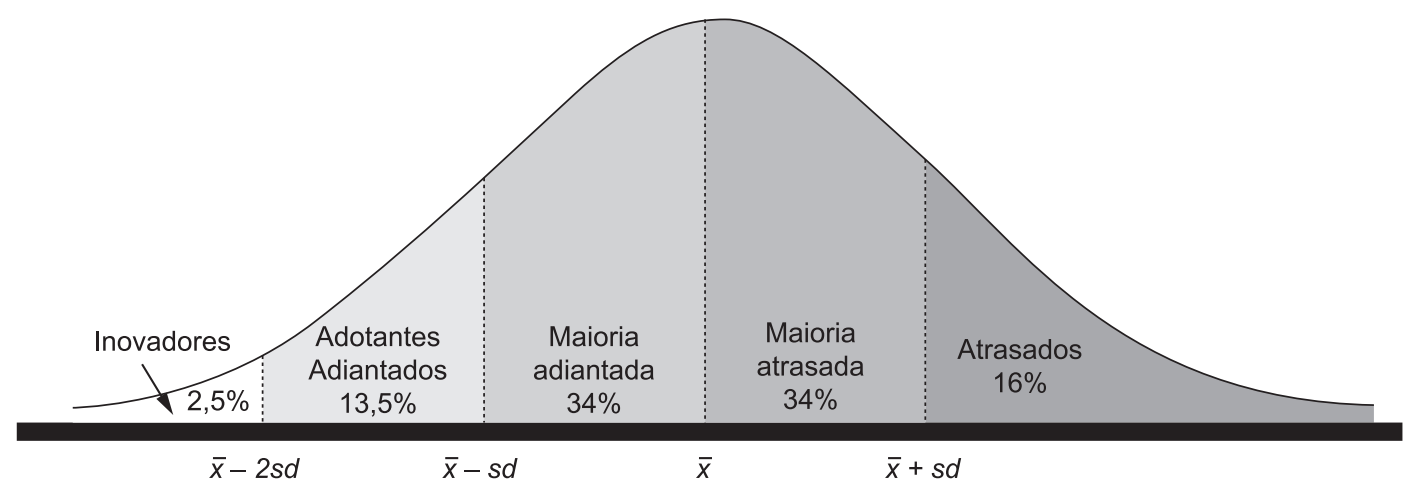

Figura 2. Categorização dos adotantes com base na inovatividade. Fonte: Rogers (1995, p. 247). 
Quadro 1. Características das categorias de adotantes.

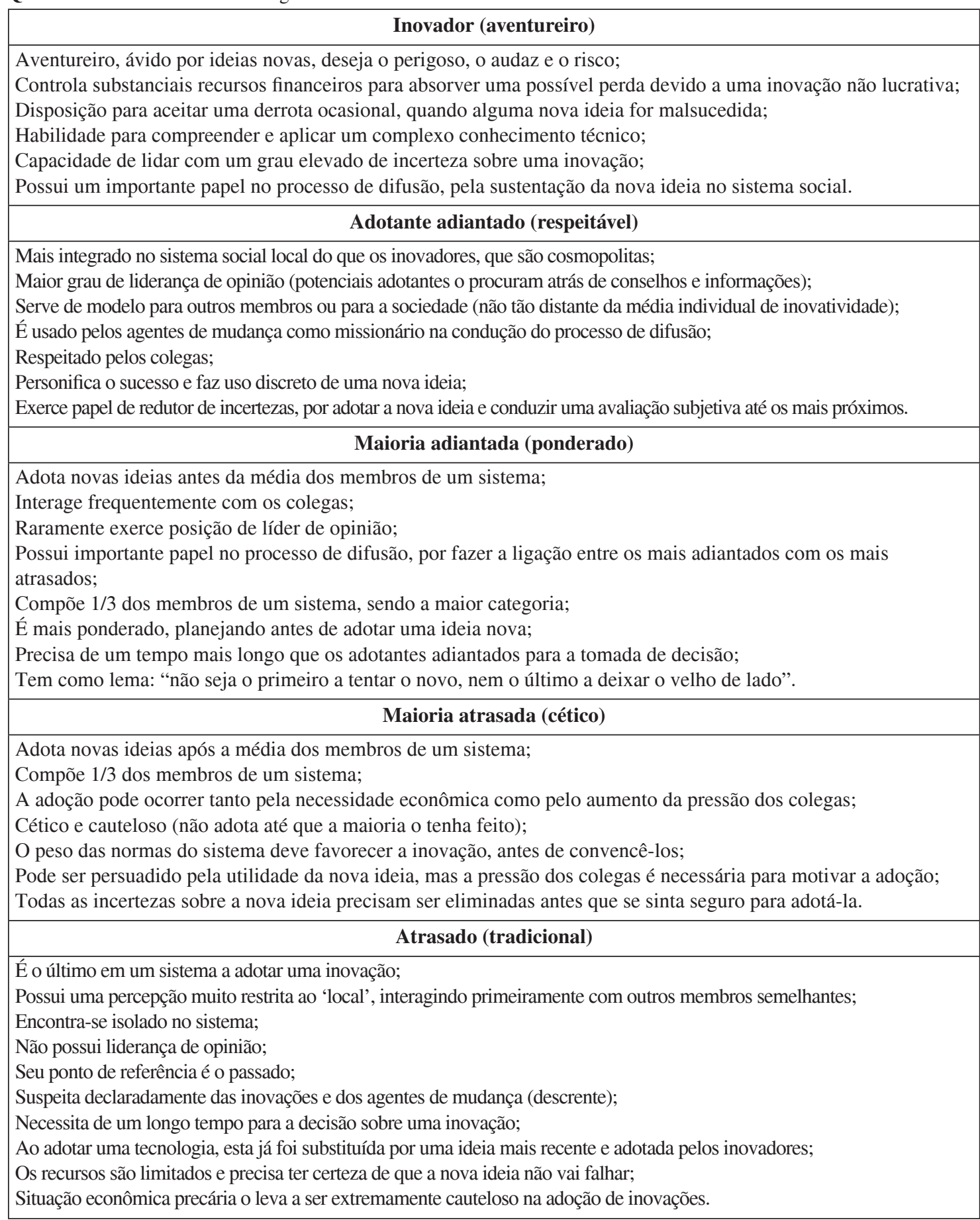

Fonte: Elaborado pelos autores a partir de Rogers (1995).

concorrência, mercado, exigência do consumidor e concorrentes) foi favorável à implantação, uma vez que o SISBOV possibilitou a informatização da atividade. Essa situação reforça o mencionado por Fortes (2004), de que a rastreabilidade ampliou o interesse por um controle informatizado além da genealogia, tornando o acompanhamento das movimentações entre piquetes, a alimentação do rebanho e as etapas de vacinação e aplicação de medicamentos, parte do cotidiano do produtor.

b) Adotantes adiantados

Em uma das propriedades, na época da informatização, em 2004, não havia qualquer tipo de controle ou registro das atividades e, após procurar 


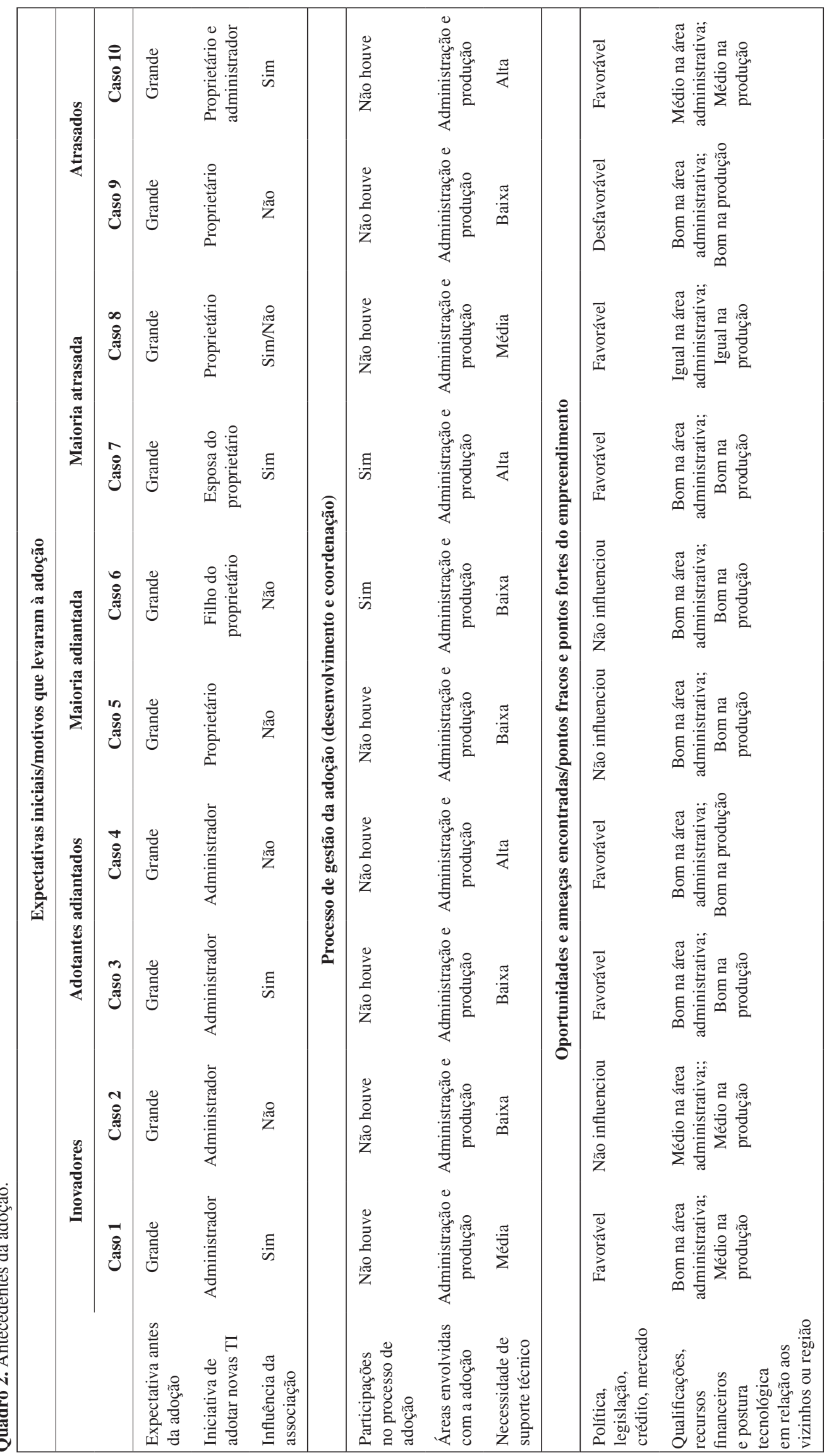


por softwares comerciais, optou-se por desenvolver um sistema próprio de gerenciamento, a partir do programa Excel $^{\circledR}$. Apesar da grande variedade de softwares disponíveis no mercado, muitas propriedades desenvolvem os próprios sistemas de gerenciamento, principalmente na área administrativa. Em casos menos frequentes, essa situação também foi observada na área de produção.

Machado (2002) destacou que os programas padronizados de gerenciamento da pecuária de corte não atendiam às necessidades dos produtores, devido à heterogeneidade da produção pecuária brasileira. Graziano da Silva (1995) apresentou outro fator que eleva o uso de sistemas customizados ou de planilhas: a não integração dos controles administrativo e produtivo, também verificada nos resultados de alguns grupos de adotantes apresentados nessa pesquisa.

O papel de uma Associação de Criadores tem sido importante na decisão de adotar TI, principalmente em relação ao software. Embora a entidade seja atuante nesse sentido, ela não oferece uma consultoria em termos de TI, uma vez que as tecnologias indicadas por ela são aquelas que complementam ou ampliam os benefícios de seu programa de melhoramento genético.

c) Maioria adiantada

O caso localizado em uma região atrasada tecnologicamente e carente de informações utiliza a tecnologia para reduzir os custos de produção. O proprietário exerce outra atividade e tem pouco tempo para se dedicar à pecuária de corte. Por isso, não são utilizados softwares de administração e de produção, e o controle é realizado de forma incipiente em um editor de texto. A justificativa é a falta de conhecimento sobre os sistemas existentes e da opção mais adequada às necessidades do negócio. Não há telefone fixo, computador e Internet, por falta de infraestrutura de telecomunicações.

Situações em que o produtor desconhece as tecnologias voltadas para a administração e a produção da atividade são comuns. A solução seria a divulgação das informações em meios de comunicação que realmente atinjam o produtor. A necessidade de informações direcionadas é mais importante para os produtores que possuem atividades paralelas, com maiores limitações de tempo. A procura por informações ocorre somente quando o problema já está instalado, conferindo uma característica reativa e expondo a atividade ao risco.

Nos casos analisados, não são realizadas compras de animais ou sêmen pela Internet ou televisão, indicando que o uso da Internet como canal de compra destina-se a produtos e equipamentos e, em menor frequência, animais e sêmen, além de confirmar a preferência da televisão como canal de comercialização para a pecuária, principalmente por meio de leilões.

\section{d) Maioria atrasada}

A expectativa era que a adoção da TI poderia facilitar o processo administrativo em todos os níveis, fato que não ocorreu, motivando o abandono de alguns projetos no início da implantação, reduzindo o uso da TI. A propriedade não possui balança eletrônica, nem software de gerenciamento da produção.

No caso que inclui três unidades de produção, duas no Estado de São Paulo e uma no Pará, a informatização iniciou-se com o controle das unidades por meio de planilhas em $\operatorname{Excel}^{\circledR} \mathrm{e}$, posteriormente, por meio de softwares específicos, como o Programa de Melhoramento Genético e o uso do software da Associação de Criadores, para registro dos animais. Foram realizados testes com um sistema de identificação eletrônica, com os resultados satisfatórios.

e) Atrasados

No primeiro caso, o proprietário tem outro negócio distante da propriedade, diminuindo sua dedicação à atividade e tornando-o mais cauteloso em relação à realização de investimentos. A propriedade possui computador, balança eletrônica e software de gerenciamento, criado pela empresa da qual o proprietário é sócio. O sistema é simples e contempla o acompanhamento de peso, nascimentos e coberturas. $\mathrm{O}$ acesso à Internet na região é deficiente, por falta de infraestrutura de telecomunicação, embora esteja localizado a $20 \mathrm{~km}$ de uma grande cidade.

O outro caso encontra-se mais atrasado em termos de TI. São três propriedades localizadas no Mato Grosso, duas ao norte do estado, região com problemas de infraestrutura e de mão de obra. Com isso, as práticas de gerenciamento utilizando TI são realizadas na sede da empresa, onde trabalha o administrador. As informações do setor pecuário são trazidas a cada visita do administrador ou do proprietário, sendo repassadas a uma empresa de consultoria, que alimenta o sistema e retorna ao administrador. Nesse momento são discutidas melhorias no software, ainda em fase de desenvolvimento.

\subsubsection{Processo de adoção}

Nesse item são discutidos os investimentos realizados em infraestrutura, a prática de testes preliminares, a percepção do uso das tecnologias adotadas e a situação atual das propriedades em relação ao uso da TI. O processo de adoção de TI está sintetizado no Quadro 3.

a) Inovadores

$\mathrm{O}$ investimento em infraestrutura de TI incluiu computadores, software e balança eletrônica, Internet, TV por satélite e telefonia celular. A Internet é acessada via satélite na maioria das propriedades da região, uma vez que o tamanho das propriedades inviabiliza a instalação de antenas para atender tão poucos clientes. $\mathrm{O}$ acesso via satélite possui custo elevado e restringe o número de usuários. 


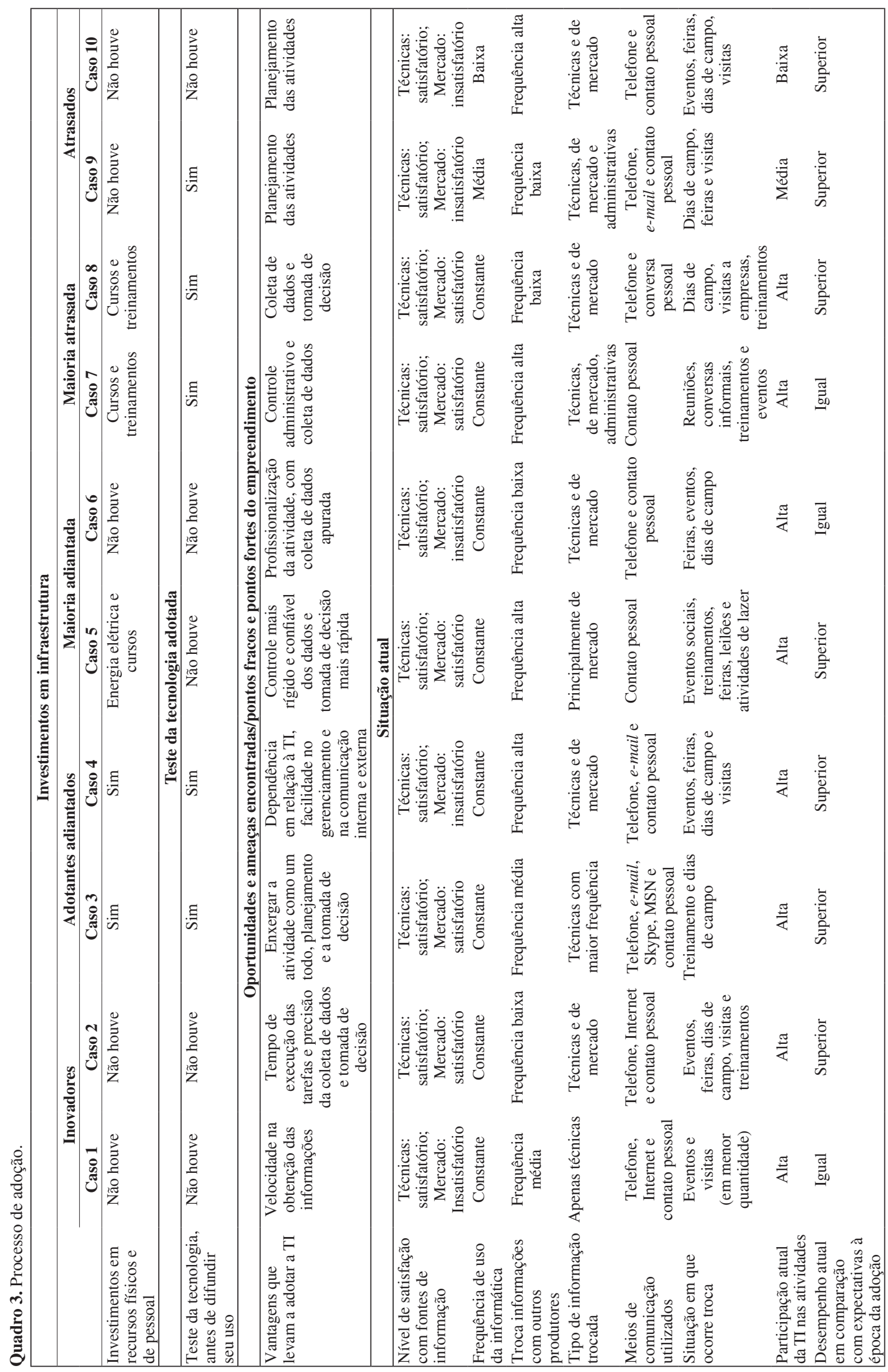


A adoção de tecnologias na pecuária tem causado um impacto positivo significativo na qualificação dos recursos humanos, indicando um aumento no grau de instrução, segurança e bem-estar dos funcionários. Já o nível de satisfação em relação às principais fontes de informação entre as propriedades estudadas foi diferente. Características individuais, o grau de exigência do tomador de decisão, o nível de conhecimento em relação à atividade, a formação profissional e a posição ocupada dentro da propriedade, concorrem para ampliar ou diminuir essa diferença.

A rede de relacionamentos pessoal é outro fator a ser destacado, podendo potencializar ou não os resultados das tomadas de decisão do administrador. Com a adoção da TI, a troca de informações é facilitada, uma vez que não existe a barreira da distância. Entretanto, os dois casos mostraram que a frequência de troca de informações com outros produtores não foi afetada pela adoção da TI.

b) Adotantes adiantados

$\mathrm{O}$ investimento em infraestrutura foi em computadores, impressora, scanner, copiadora, software, balança eletrônica, antena e decodificador. A balança foi adquirida juntamente com a estrutura de pesagem, elevando os investimentos iniciais. Em um dos casos, o investimento em infraestrutura de TI foi significativamente maior, devido à aquisição de uma balança rodoviária e à construção de instalações.

A adoção de tecnologia possibilitou o planejamento da atividade, melhoria no gerenciamento e na comunicação interna e externa, além da tomada de decisão com uma visão holística do negócio. Os sentimentos de dependência em relação à informática e o receio da tecnologia se tornar obsoleta rapidamente também foram evidenciados.

As propriedades trocam informações com outros produtores, porém em intensidade e frequência diferentes. Os meios mais utilizados para comunicação foram: o telefone, e-mail, $\mathrm{MSN}^{\circledR}{ }^{\circledR} \mathrm{Skype}^{\circledR}$, mas a preferência é maior pela presença física, em reuniões de um Núcleo de Criadores local, realizadas para treinamento e dias de campo. A visita a outros produtores não é uma prática comum.

\section{c) Maioria adiantada}

Para suprir a falta de testes, o proprietário costuma ver os equipamentos em funcionamento em outras propriedades, para depois adotá-los. A complexidade da tecnologia, o custo e a possibilidade de poder experimentá-la e observá-la, foram destacadas por todos os grupos, como facilitadores das decisões de adoção. Na falta de testes preliminares, proprietários e administradores tendem a uma maior probabilidade de adoção se outros produtores de sua rede pessoal também adotarem. As atitudes relativas ao comportamento de compra também são aprendidas por meio da informação de outros indivíduos, situação observada nos casos estudados, a partir do contato pessoal e visita a outras propriedades.

Em um dos casos, o controle de custos é realizado de forma incipiente, por falta de um sistema que disponibilize todas as funções. Mesmo com a disponibilidade de programas com opções diversas de planilhas e fórmulas mais adequadas para esse fim, o proprietário não os utiliza, por não saber operá-los. Com esse sistema de gerenciamento mais simplificado, poucas informações são controladas na produção (peso individual e controle de descartes) e as cotações são obtidas em jornais e na Internet.

d) Maioria atrasada

Nos dois casos, foram realizados testes com TI antes da adoção, com resultados diferentes. No primeiro, foram testados diversos softwares, mas o processo de adoção foi descontinuado em razão de sua complexidade. No outro caso, o teste foi realizado com um sistema de identificação eletrônica, em um dia de campo com a empresa fornecedora e a presença de outros produtores, tornando o período do teste curto. Embora os resultados tenham sido satisfatórios, o alto custo de implantação foi limitante para sua adoção.

Esse resultado indicou outra barreira à adoção da TI, a resistência à adoção de sistemas de identificação eletrônica, apesar do reconhecimento dos benefícios no controle e monitoramento do rebanho. O motivo dessa resistência foi o mesmo encontrado em Machado (2002) e ainda representa a principal dificuldade para a disseminação da tecnologia: o alto custo de aquisição e implantação.

O grau de satisfação das propriedades desse grupo com as fontes de informação é diferente, principalmente no que diz respeito às fontes consultadas. Apesar de não se tratar de um levantamento quantitativo, ressalta-se que o uso da Internet na atividade pecuária está relacionado à procura por notícias do setor, cotação de preços e análise do mercado agropecuário.

e) Atrasados

Os investimentos realizados em um dos casos incluíram computador, televisão (satélite e parabólica) e balança eletrônica com a estrutura de curral. No outro caso, foram realizados investimentos em equipamentos, consultoria e infraestrutura, para levar energia elétrica até uma das unidades de produção. A falta de energia elétrica e estrutura de telecomunicações na região dificultam a adoção de tecnologias. Por isso, o uso de informática é baixa, motivados pela precariedade do sistema utilizado em um caso e pelo processo de informatização em andamento, em outro.

A frequência de troca de informações com outros produtores é diferente nas duas propriedades e se resumem aos dias de campo e exposições. Porém, a falta de tempo é um limitador para a participação frequente nesses eventos, levando um dos proprietários a visitar outros produtores, a fim de observar os manejos adotados. A visita pessoal foi considerada 
a melhor forma para troca de informações entre os produtores.

\subsubsection{Impactos da adoção}

Os impactos da adoção da TI foram analisados a partir de mudanças internas e externas ao empreendimento rural, dos benefícios obtidos e dos obstáculos identificados no decorrer da adoção (Quadro 4).

a) Inovadores

Uma das funções afetadas pela adoção da TI foram os recursos humanos. As propriedades caminham para ter funcionários alfabetizados e cada vez mais qualificados, mas ainda existem funcionários que não percebem essa necessidade, tornando-se inaptos para lidar com as novas tecnologias. Essa percepção, quando tardia, pode levar ao desligamento desses indivíduos.

A TI teve um impacto positivo para o controle contábil, armazenamento e processamento dos dados, o que não ocorreu para a coleta de dados da produção e compras pela Internet. Foram observadas mudanças positivas no comportamento dos funcionários de campo, a partir do uso da televisão no acompanhamento de programas técnicos. O computador, software e Internet, embora não sejam utilizados por eles, foram incorporados no dia a dia dos funcionários, que solicitam a busca de informações na Internet e consultas nas fichas dos animais. Essa mudança no comportamento tem refletido na gestão dos recursos humanos, com a implantação de uma política de valorização dos funcionários, incluindo a remuneração e o bem-estar.

A adoção de TI também apresentou problemas nos dois casos. Além da qualificação do pessoal, que prejudicou a alimentação do software em um dos casos, e do baixo comprometimento dos funcionários com a qualidade dos dados coletados, os serviços de apoio e a incompatibilidade entre sistemas surgiram como problemas decorrentes da adoção. A incompatibilidade entre tecnologias foi observada na transmissão dos dados para o Programa de Melhoramento Genético.

\section{b) Adotantes adiantados}

Foram observadas mudanças na área administrativa, com um impacto significativo nos recursos humanos, por meio de treinamentos ou dispensas causadas pela resistência cultural ou baixa instrução, e uma maior preocupação com controle contábil das atividades. A atuação dos funcionários mudou com o avanço tecnológico e a cobrança por resultados. A partir do uso das planilhas, os funcionários passaram a executar tarefas planejadas para o dia, sem permissão para fazer algo além do estabelecido. Houve melhoria na remuneração, com a implantação de uma política de incentivos.
Todos os casos, independentemente do grupo a que pertencem, experimentaram benefícios relacionados ao aprendizado, aprimoramento de processos, rapidez na tomada de decisão e redução de custos, este em menor quantidade. Esses retornos intangíveis incluem ainda, a qualidade dos dados e do produto final, a integração de processos da empresa, agilidade, melhoria no relacionamento com clientes e fornecedores.

\section{c) Maioria adiantada}

Nos dois casos, os impactos decorrentes da adoção da TI foram maiores nos recursos humanos, ressaltando que, em um dos casos, não havia coleta de dados anteriormente à implantação das tecnologias. $\mathrm{O}$ processo de informatização provocou alterações na estrutura organizacional, gerou resistência cultural por parte dos funcionários menos qualificados e, em alguns casos, resultados pouco ou nada satisfatórios com o uso da TI.

A mudança na imagem do negócio foi verificada nos dois casos e, da mesma forma que os grupos anteriores, os fornecedores procuram estar presentes nessas propriedades para aumentar a visibilidade na região. O impacto pelo lado dos clientes foi verificado a partir da constatação por parte do mercado do controle realizado no rebanho, aumentando a procura pelos animais.

\section{d) Maioria atrasada}

Foram observados efeitos positivos da TI internamente, como a realocação de funções, reengenharia de processos e maior integração entre áreas ou atividades. Os efeitos da TI nos processos afetaram os funcionários, que foram trocados de função ou demitidos, quando não se adequavam à nova rotina. A tomada de decisão foi, em parte, descentralizada, passando a ser compartilhada, com dados analisados por mais de uma pessoa. Cada unidade passou a tomar sua decisão, enquanto as decisões estratégicas são realizadas na sede, local de moradia dos proprietários. A ausência da Internet nas demais unidades dificulta o gerenciamento à distância.

Na coleta de dados, ainda há anotações erradas, pois a prática exige anotação dos dados em papel e posterior inserção no sistema. Uma forma de contornar essa dificuldade seria alimentar o sistema no local do manejo, permitindo diagnosticar problemas no ato da operação, mas o despreparo do gerente, a necessidade de treinamento e a ausência da Internet no local dificultam a implantação dessa operação.

As dificuldades observadas no grupo incluem problemas na utilização da TI durante o processo de implantação, na coleta de dados e no uso dos sistemas, devido, principalmente, à desqualificação dos funcionários. A infraestrutura de telecomunicações dificultou a implantação da Internet, pois a tecnologia disponível era lenta e o acesso de baixa qualidade. Duas dificuldades foram destacadas: a precariedade 


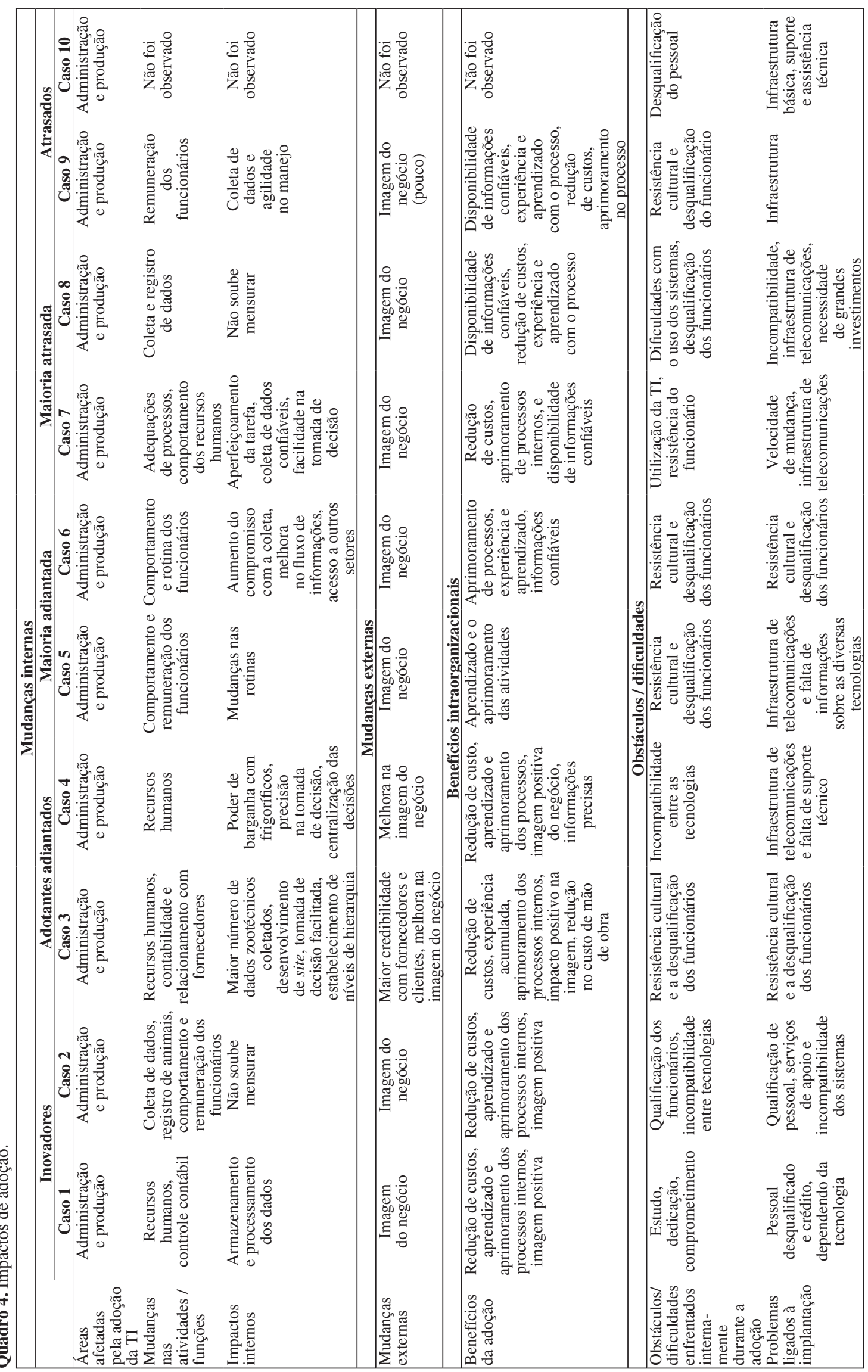


ou ausência de serviços de telefonia e energia elétrica, e a ausência de provedores de Internet.

\section{e) Atrasados}

O impacto da adoção da TI nesse grupo apresenta uma particularidade. Em um dos casos, a atividade passa pelo processo de informatização, limitando a percepção de mudanças e benefícios decorrentes do processo. Alguns funcionários demonstraram certa resistência inicial, que aos poucos foi superada com o auxílio de colegas mais experientes. Os benefícios dessa adoção foram a disponibilidade de informações confiáveis, experiência e aprendizado do processo e redução de custos. O aprimoramento no processo, principalmente na rotina de pesagem, foi alterado de forma positiva, com ganhos significativos no manejo (profilaxia e pesagem) e registro dos dados.

Dentre os obstáculos encontrados, verificou-se a resistência cultural dos funcionários. $\mathrm{O}$ medo do desconhecido, a falta de instrução e a imposição pela legislação agravam essa situação. A forma encontrada para superar esse problema foi a introdução de tecnologias com uma linguagem didática e simplificada. Essa situação já foi percebida por algumas empresas de TI, que passaram a redesenhar displays e desenvolver menus de fácil compreensão e utilização, com teclas coloridas para as funções.

\section{Conclusões}

Os casos apresentados sugerem diferentes posturas administrativas a partir da existência de uma infraestrutura de telecomunicações que permita minimizar distâncias e tornar possíveis negócios anteriormente inviáveis, em função da localização das unidades produtivas, possibilitando o acompanhamento do mercado e a realização de transações com menores custos. As organizações rurais que adotaram a Internet possuem caráter mais empresarial; nível tecnológico mais alto na produção e na administração; proprietários ou administradores mais novos e/ou com nível superior; e o fato dos proprietários manterem outras atividades, principalmente econômicas, fora da propriedade.

Os resultados da pesquisa empírica permitiram concluir que a utilização de sistemas customizados ou planilhas eletrônicas na gestão das propriedades ocorre com frequência, pois os programas padronizados não atendem às necessidades dos produtores, devido à heterogeneidade da produção pecuária brasileira e a não integração dos controles administrativos e produtivos. Além disso, o processo de informatização provocou alterações na estrutura organizacional das propriedades e gerou resistência dos funcionários menos qualificados, resultando em mudanças internas, como realocação de funções, reengenharia de processos e maior integração com outras áreas ou atividades desenvolvidas.
O uso da Internet está mais relacionado à procura por notícias do setor, cotação de preços e análise do mercado agropecuário, do que como canal de compra. Quando utilizada para esse fim, é mais frequente para produtos e equipamentos, do que para compra de animais e sêmen. Como obstáculos relacionados à adoção da TI, foram verificados a precariedade ou ausência de serviços de telefonia, de energia elétrica e de provedores de Internet.

$\mathrm{O}$ comportamento do produtor em relação à TI indicou atitudes favoráveis e desfavoráveis, de forma a explicar os comportamentos diferenciados observados entre propriedades de um mesmo grupo. Foi possível concluir que as propriedades mais atrasadas apresentaram atitudes cautelosas em relação à TI, devido à incerteza em relação aos resultados, e as mudanças observadas se concentraram na área administrativa, com um impacto significativo nos recursos humanos, no que se refere a treinamentos ou dispensas provocadas pela resistência cultural ou baixo grau de instrução.

Por fim, os resultados sugerem a importância da formulação e implementação de políticas para adoção e uso de TI no campo, visando garantir acesso às tecnologias para pequenos e médios produtores, cujas propriedades não são organizadas nos moldes empresariais.

\section{Referências}

ADRIAN, A. M.; NORWOOD, S. H.; MASK, P. L. Producers' perceptions and attitudes toward precision agriculture technologies. Computers and Electronics in Agriculture, v. 48, n. 3, p. 256-271, 2005. http:// dx.doi.org/10.1016/j.compag.2005.04.004

ALVAREZ, J.; NUTHALL, P. Adoption of computer based information systems: the case of dairy farmers in Canterbury, NZ, and Florida, Uruguay. Computers and Electronics in Agriculture, v. 50, n. 1, p. 48-60, 2006. http://dx.doi.org/10.1016/j.compag.2005.08.013

BATTE, M. T. Changing computer use in agriculture: evidence from Ohio. Computers and Electronics in Agriculture, v. 47, n. 1, p. 1-13, 2005. http://dx.doi. org/10.1016/j.compag.2004.08.002

BATZ, F. J.; JANSSEN, W.; PETERS, K. J. Predicting technology adoption to improve research priority-setting. Agricultural Economics, v. 28, n. 2, p. 151-164, 2003. http://dx.doi.org/10.1111/j.1574-0862.2003.tb00248.x

DIEDEREN, P. et al. Innovation adoption in agriculture: innovators, early adopters and laggards. Cahiers d'économie et sociologie rurales, n. 67, p. 29-50, 2003. Disponível em: <http://www.inra.fr/Internet/ Departements/ESR/publications/cahiers/pdf/diederen. pdf>. Acesso em: 16 jan. 2006.

FERREIRA, L. B.; RAMOS A. S. M. Tecnologia da informação: commodity ou ferramenta estratégica? Revista de Gestão da Tecnologia e Sistemas de Informação, v. 2, n. 1, p. 69-79, 2005. Disponível em: 
$<$ http://www.jistem.fea.usp.br/index.php/jistem/article/ download/14/9>. Acesso em: 27 dez. 2005.

FIGUEIRA, A. S. et al. Impactos da tecnologia da informação na dimensão competitiva de agentes da cadeia produtiva do leite. In: CONGRESSO BRASILEIRO DE ECONOMIA E SOCIOLOGIA RURAL, 42., 2004, Campo Grande. Anais... Campo Grande, SOBER, 2004. 1 CDROM.

FORTES, G. Como aproveitar melhor a informática na pecuária. Revista DBO Rural, v. 23, n. 288, p. 98-106, 2004.

FRANCISCO, V. L. F. S. Acesso do setor rural à Internet no estado de São Paulo. Informações Econômicas, v. 33, n. 5, p. 53-56, 2003.

FREITAS, H. M. R.; RECH, I. Problemas e ações na adoção de novas tecnologias de informação. Revista de Administração Contemporânea, v. 7, n. 1, p. 125-150, 2003.

FURLAN, J. D.; IVO, I. M. Megatendências da tecnologia da informação. São Paulo: Makron Books, 1992. 88p.

GRAZIANO DA SILVA, J. Impactos das tecnologias da informação na agricultura. Revista de Economia e Sociologia Rural, v. 34, n. 2, p .7-30, 1995.

HOLLIFIELD, C. A.; DONNERMEYER, J. F. Creating demand: influencing information technology diffusion in rural communities. Government Information Quarterly, v. 20, n. 2, p.135-150, 2003. http://dx.doi. org/10.1016/S0740-624X(03)00035-2

MACHADO, J. G. C. F. A adoção da identificação eletrônica de animais na gestão do empreendimento rural: um estudo multicaso na pecuária de corte. 2002. 129 f. Dissertação (Mestrado em Engenharia de Produção)-Universidade Federal de São Carlos, São Carlos, 2002.

MACHADO, J. G. C. F.; NANTES, J. F. D. Utilização da identificação eletrônica de animais e da rastreabilidade na gestão da produção da carne bovina. Revista Brasileira de Agroinformática, v. 3, n. 1, p. 41-50, 2000.

MARRA, M.; PANNELL, D. J.; GHADIM, A. A. The economics of risk, uncertainty and learning in the adoption of new agricultural technologies: where are we on the learning curve? Agricultural Systems, v. 75, n. 2-3, p. 215-234, 2003. http://dx.doi.org/10.1016/ S0308-521X(02)00066-5
MINÉU, H. F. S. Tecnologia de informação e estratégias de produtores rurais: um estudo multicaso em Uberaba, MG. 2002. 254 f. Dissertação (Mestrado em Administração)-Universidade Federal de Lavras, Lavras, 2002.

PANNELL, D. J. et al. Understanding and promoting adoption of conservation practices by rural landholders. Australian Journal of Experimental Agriculture, v.46, n.11, p.1407-1424, 2006. http://dx.doi.org/10.1071/ EA05037

PARASURAMAN, A. Technology Readiness Index (TRI): a multiple-item scale to measure readiness to embrace new technologies. Journal of Service Research, v. 2, n. 4, p. 307-320, 2000. http://dx.doi. org/10.1177/109467050024001

PARASURAMAN, A.; COLBY, C. Techno-ready marketing: how and why your customers adopt technology. New York: The Free Press, 2001.

ROCHA, A.; CHISTENSEN, C. Marketing: teoria e prática no Brasil. São Paulo: Atlas, 1999. 284 p.

ROGERS, E. M. Diffusion of innovations. 4th ed. New York: The Free Press, 1995.

SANTOS JUNIOR, S.; FREITAS, H.; LUCIANO, E. M. Dificuldades para o uso da tecnologia da informação. RAE-eletrônica, v. 4, n. 2, 2005. Disponível em: http:// www.scielo.br/pdf/raeel/v4n2/v4n2a05.pdf. Acesso em: 02 jun. 2006.

SCHIEFER, G.; ZAZUETA, F. Information technology for food security in a global environment. In: KRACHT, U.; SCHULZ, M. (Eds.) Food Security and Nutrition in the Process of Globalization. Berlin: LIT Verlag, 2004.

SHEIKH, A. D.; REHMAN, T.; YATES, C. M. Logit models for identifying the factors that influence the uptake of new 'no-tillage' technologies by farmers in the rice-wheat and the cotton-wheat farming systems of Pakistan's Punjab. Agricultural Systems, v. 75, n. 1, p. 79-95, 2003. Disponível em: http://www.elsevier. com/locate/agsy. Acesso em: 04 fev. 2003.

YAMAGUCHI, L. C. T. Gestão informatizada de fazendas e cooperativas agropecuárias. In: WORKSHOP O AGRONEGÓCIO NA SOCIEDADE DA INFORMAÇÃO - AGROSOFT, 2002, Brasília. Anais... Brasília: Agrosoft, 2002. Disponível em: www.agrosoft. com/ag2002/workshop/imprimir.php?page=115. Acesso em: 23 abr. 2002. 